\title{
The functional status, rehospitalization, and hospital cost reduction in geriatric patients after the implementation of the universal health coverage program in the national referral hospital Indonesia
}

Czeresna Heriawan Soejono, Hari Sutanto

pISSN: 0853-1773 • elSSN: 2252-8083 https://doi.org/10.13181/mji.v28i4.3214 Med J Indones. 2019;28:358-64

Received: October 15, 2018

Accepted: May 29, 2019

\section{Authors' affiliations:}

Department of Internal Medicine, Faculty of Medicine, Universitas Indonesia, Cipto Mangunkusumo Hospital, Jakarta, Indonesia

\section{Corresponding author:}

Czeresna Heriawan Soejono

Department of Internal Medicine, Faculty of Medicine, Universitas Indonesia, Cipto Mangunkusumo Hospital, Jalan Diponegoro No. 71, Kenari, Senen, Central Jakarta 10430, DKI Jakarta, Indonesia

Tel/Fax: +62-21-31900275

E-mail: ch_soejono@yahoo.com

\begin{abstract}
BACKGROUND Universal health coverage program (UHCP) might implicate negatively toward geriatric care with its impact on higher cost. The evaluation had to be made, especially in functional status, rehospitalization, and cost-effectiveness.
\end{abstract}

METHODS Retrospective cohort study with historical control was done. Seventy two geriatric inpatients in the pre-UHCP group and 86 in the UHCP group were recruited from Cipto Mangunkusumo Hospital, Jakarta, Indonesia. Subjects with geriatric syndromes admitted from July to December 2013 (pre-UHCP era) and January to June 2014 (UHCP era). Functional status changes, rehospitalization, and process indicators were observed. Cost reduction was calculated using the incremental cost-effectiveness ratio (ICER), whereby costs, functional status changes, and rehospitalization of both groups were used to identify the differences.

RESULTS Proportions of functional status increase were $35.3 \%$ and $34.8 \%$ in the preUHCP and UHCP groups, respectively $(p=1.00)$ and the decrease were $5.9 \%$ and $4.5 \%$ in the pre-UHCP and UHCP group, respectively $(p=1.00)$. Rehospitalization rates were $21.7 \%$ and $18.1 \%(p=0.603)$ in the pre-UHCP and UHCP groups, respectively. Mean hospital expenses were between 17.1 million IDR (1,221 USD; 1 USD = 14,000 IDR) for the pre-UHCP group and 20.8 million IDR (1,486 USD) for the UHCP group. ICER showed that hospitalization cost was 3.7 million IDR (264 USD) higher to increase 1 activity of daily living score in the UHCP era. As for rehospitalization, the cost was 600,000 IDR (43 USD) less, with $3.6 \%$ smaller in readmission.

CONCLUSIONS There was no changes in patients' functional status after the UHCP implementation. There was a reduction in rehospitalization with lower cost in the UHCP era.

KEYWORDS functional status, geriatrics, health insurance, hospital cost, hospitalization
In 2015, the percentage of the elderly population was $9.0 \%$, and it will increase to $19.7 \%$ in the year 2045. In 2040, Indonesia will have 38,825,000 elderly people with an average life expectancy of 72.51 years in men and 74.05 years in women., ${ }^{1,2}$ Consequently, the number of geriatric population will increase and play an important role in the epidemiological transition. Increase morbidity and hospital cost in this vulnerable population will be of high importance if not addressed properly. ${ }^{2,3}$ With the commencement of jaminan kesehatan nasional/universal health coverage program (UHCP) in 2014, the geriatric patient was at higher risk of having a lower quality of care since the prospective payment scheme in this program does not always match with the hospital management funding system and limited reimbursement from the program itself. The UHCP payment system relies on clinical pathways and other clinical guidelines, whereas the care of patient in the geriatric population is very customized according to their specific needs; this discrepancy 
might put geriatric patients at risk of lower quality of care outcome (represented by the measurement of decrease in functional status on discharge), increase in rehospitalization, or increase of hospital cost.

Since the commencement of UHCP in January 2014, there has been no study regarding the functional status outcome and rehospitalization concerning the cost-effectiveness in acute geriatric patients. ${ }^{4}$ The objective of the study was to observe whether the implementation of UHCP in Cipto Mangunkusumo Hospital would give a negative impact on the functional status on discharge in geriatric patients, increase the rate of rehospitalization, or increase the cost of hospitalization.

\section{METHODS}

This is a retrospective cohort study with historical control carried out at Cipto Mangunkusumo Hospital, Jakarta, Indonesia. The study was divided into two groups. The control group was patients hospitalized from July to December 2013 (pre-UHCP group) and the case group was patients hospitalized from January to June 2014 (UHCP group). Inclusion criteria were patients with geriatric syndromes, including acute confusional state/delirium, falls, incontinence, dementia, immobility, depression, and pressure ulcer. Exclusion criteria were death within the first 24 hours or transfer to another hospital before completion observation. Variables measured were changes in functional status using the Barthel score of activity of daily living ( $A D L$ ), number of rehospitalization, and hospital cost. Rehospitalization was measured 30 days after hospital discharge by contacting the patients or the families via telephone. ${ }^{5}$ Barthel score of ADL or ADL score was an instrument used to calculate a person's ability to perform basic ADLs (feeding, controlling bowels, controlling the bladder, grooming, dressing, toileting, bathing, transferring, mobilizing, and taking stairs). ${ }^{6}$ Each activity would be scored and summed. The classification of the score were totally dependent (score 0-4), heavily dependent (score 5-8), moderately dependent (score 9-11), mildly dependent (score 12-19), fully independent (score 20); the maximum score 20.7 The minimum number of subjects needed was estimated using the sample size formula for different proportions. Subjects were recruited consecutively. Ethical clearance of the study was obtained from the
Ethical Committee of Faculty of Medicine, Universitas Indonesia (No: 753/UN2.F1/ETIK/2014).

\section{Statistical analysis}

SPSS software version 20 (IBM Corp, USA) was used for data analysis after the normality test was performed. Numerical data were presented in means and standard deviation for normally distributed data, and the median was used if otherwise. Categorical data were presented in proportion and percentage. Incremental cost-effectiveness ratio (ICER) was presented in a plot diagram. Unpaired t-test was used to examine the means' difference for normally distributed data, whereas the Mann-Whitney nonparametric test was used if otherwise. Chi-square test or Fisher's exact test was used to examine the proportion difference. A cost-effectiveness analysis was done by calculating the ICER. Functional statusrelated ICER was obtained by dividing the difference of the mean costs during hospitalization of both the UHCP and non-UHCP groups by the difference of their mean ADL score changes during hospitalization. The same formula was used to calculate rehospitalizationrelated ICER, but the difference of the mean costs of the two groups was divided by the difference of their rehospitalization proportions. Process indicators were assessed to omit the possibility of too close observation that might influence the result. ${ }^{8,9}$

\section{RESULTS}

The median ages in the pre-UHCP (72 subjects) and UHCP groups (86 subjects) were 70 and 67 years, respectively. The age distribution and other characteristics from the two groups were comparable (Table 1).

The type of diagnosis from each group was relatively similar; but in the pre-UHCP group, there was fracture diagnosis with hospitalization indication that was similar to that with stroke in the UHCP group, from the functional status perspective (Table 2). Comparability of diagnosis in each group was important to see the severity level of diseases as geriatric patients are always admitted with a complex health condition.

Regarding the functional status, only 134 of the 158 subjects have a complete functional status data. Although the difference of ADL score in the UHCP group $(2[-5-15])$ was higher compared with that in 
Table 1. Basic characteristics of the pre-UHCP and UHCP groups

\begin{tabular}{|c|c|c|}
\hline Characteristics & Pre-UHCP, $n(\%)(N=72)$ & UHCP, $n(\%)(N=86)$ \\
\hline Age (years), median (min-max) & $70(60-86)$ & $67(60-85)$ \\
\hline \multicolumn{3}{|l|}{ Age category (years) } \\
\hline $60-69$ & $33(45.8)$ & $55(64)$ \\
\hline $70-79$ & $33(45.8)$ & $26(30.2)$ \\
\hline$\geq 80$ & $6(8.3)$ & $5(5.8)$ \\
\hline Male sex & $35(48.6)$ & $34(39.5)$ \\
\hline \multicolumn{3}{|l|}{ Education status } \\
\hline$\leq$ Primary school & $18(25.0)$ & $27(31.4)$ \\
\hline High school & $14(19.4)$ & $20(23.3)$ \\
\hline$\geq$ Diploma & $40(8.3)$ & $39(45.3)$ \\
\hline \multicolumn{3}{|l|}{ Marital status } \\
\hline Married & $41(56.9)$ & $51(59.3)$ \\
\hline Not married & $1(1.4)$ & $0(0.0)$ \\
\hline Widow/Widower & $12(16.7)$ & $17(19.8)$ \\
\hline No data & $18(25)$ & $18(20.9)$ \\
\hline Self-discharge & $14(19.4)$ & $12(14.0)$ \\
\hline $\mathrm{BMI}^{*}$ median $(\min -\max )$ & $23.419(13.2-32)$ & $22.361(16-34.1)$ \\
\hline \multicolumn{3}{|l|}{ BMI category } \\
\hline$<18.5 \mathrm{~kg} / \mathrm{m}^{2}$ & $9(12.5)$ & $13(15.1)$ \\
\hline $18.5-22.9 \mathrm{~kg} / \mathrm{m}^{2}$ & $14(19.4)$ & $15(17.4)$ \\
\hline$>22.9 \mathrm{~kg} / \mathrm{m}^{2}$ & $27(37.5)$ & $20(23.3)$ \\
\hline No data & $22(30.6)$ & $38(44.2)$ \\
\hline \multicolumn{3}{|l|}{ Dependency status } \\
\hline Independent & $2(2.8)$ & $4(4.7)$ \\
\hline Mildly dependent & $18(25)$ & $17(19.8)$ \\
\hline Moderately dependent & $14(19.4)$ & $14(16.3)$ \\
\hline Severely dependent & $16(22.2)$ & $13(15.1)$ \\
\hline Totally dependent & $18(25)$ & $18(20.9)$ \\
\hline No data & $4(5.6)$ & $20(23.2)$ \\
\hline \multicolumn{3}{|l|}{ Difference of ADL (discharge-admission) } \\
\hline Median difference of ADL score & 1 & 2 \\
\hline Hospital cost ( $\times 1,000,000$ IDR) & 17.1 & 20.8 \\
\hline \multicolumn{3}{|l|}{ Rehospitalization } \\
\hline Proportion without rehospitalization (\%) & 78.3 & 81.9 \\
\hline Hospital cost $(\times 1,000,000$ IDR) & 20.0 & 19.4 \\
\hline
\end{tabular}

$\mathrm{UHCP}=$ universal health coverage program; $\mathrm{BMI}=$ body mass index; $\mathrm{ADL}=$ activity of daily living *Pre-UHCP $(\mathrm{N}=50)$; UHCP $(\mathrm{N}=72) ; 26$ subjects were missing due to loss to follow up the pre-UHCP group $(1[-5-13])$, as seen in Table 3 , the proportions of those with increased $A D L$, steady ADL, or decreased ADL score were relatively similar.

However, the proportion of those who were discharged with independent functional status was higher in the UHCP group (from $6.1 \%$ to $19.7 \%$ or an increase of $13.6 \%$ ) compared with that in the pre-UHCP group (from $2.9 \%$ to $7.4 \%$ or an increase of $4.5 \%$ ), as seen in Figure 1.

Process indicators were assessed to omit the possibility of too close observation that might influence the results mentioned earlier. The proportions of functional status similarity assessed by a physician, physiotherapist, or psychiatrist in the pre-UHCP and 
Table 2. The top 10 diagnoses in the pre-UHCP and UHCP groups

\begin{tabular}{lcccc}
\hline No. & Pre-UHCP & $\mathrm{n}(\%)(\mathrm{N}=70)$ & UHCP & $\mathrm{n}(\%)(\mathrm{N}=81)$ \\
\hline 1. & Pneumonia & $43(61.4)$ & Pneumonia & $57(70.4)$ \\
2. & Acute confusional state & $23(32.9)$ & Acute confusional state & $29(35.8)$ \\
\hline 3. & Infection other than pneumonia & $18(25.7)$ & Infection other than pneumonia & $27(33.3)$ \\
\hline 4. & Diabetes & $15(21.4)$ & Diabetes & $16(19.8)$ \\
\hline 5. & Malignancy & $13(18.6)$ & Chronic heart failure & $14(17.3)$ \\
6. & Gastrointestinal bleeding & $12(17.1)$ & Gastrointestinal bleeding & $11(13.6)$ \\
7. & Chronic heart failure & $12(17.1)$ & Sepsis & $11(13.6)$ \\
8. & Sepsis & $10(14.3)$ & CKD on dialysis & $9(11.1)$ \\
9. & Fracture & Malignancy & $8(9.9)$ \\
10. & CKD on dialysis & Stroke & $7(8.6)$ \\
\hline
\end{tabular}

$\mathrm{UHCP}=$ universal health coverage program; $\mathrm{CKD}=$ chronic kidney disease

Table 3. The difference in ADL Barthel score

\begin{tabular}{lccc}
\hline Outcomes & $\begin{array}{c}\text { Pre-UHCP } \\
(\mathrm{N}=68)\end{array}$ & $\begin{array}{c}\text { UHCP } \\
(\mathrm{N}=66)\end{array}$ & $p^{*}$ \\
\hline $\begin{array}{l}\text { ADL Barthel score, } \\
\text { median (min-max) }\end{array}$ & & & \\
$\quad \begin{array}{lcc}\text { Before hospitalization } \\
\text { During discharge }\end{array}$ & $9(0-20)$ & $9(2-20)$ & \\
\hline $\begin{array}{l}\text { Score difference } \\
\text { Proportion of changes, }\end{array}$ & $1(-5-13)$ & $12.5(0-20)$ & 0.509 \\
$\mathrm{n}(\%)$ & & & \\
\hline $\begin{array}{l}\text { Increased } \\
\text { Steady }\end{array}$ & $24(35.3)$ & $23(34.8)$ & 1.0 \\
\hline Decreased & $40(58.8)$ & $40(60.6)$ & \\
\hline
\end{tabular}

$A D L=$ activity of daily living; $U H C P=$ universal health coverage program * $p$-value for nonparametric Kolmogorov-Smirnov test

UHCP groups were $14.4 \%$ and $12.3 \%$, respectively $(p=0.96)$. The proportions of a functional reablement program done by nurses in the pre-UHCP and UHCP groups were $44.5 \%$ and $35.9 \%$, respectively ( $p=0.36$ ). These process indicators show that the result of functional status outcome was not due to too close observation (Table 4).

Observation on rehospitalization rate could only be performed on 132 subjects (60 in the pre-UHCP group and 72 in the UHCP group) because 26 subjects were lost to follow-up. The rate of rehospitalization in each group was 13 patients, with proportions of $21.7 \%$ and $18.1 \%$ in the pre-UHCP and UHCP groups, respectively (3.6\% difference; $p=0.603$ ).

The hospital cost difference between pre-UHCP (20.8 million IDR) and UHCP group (17.1 million IDR) was 3.7 million IDR (264 USD; 1 USD = 14,000 IDR). This means that the cost of increasing 1 ADL score would be 264 USD. Meanwhile, in case of rehospitalization ( $n=132$ patients), the difference between two groups (20 million IDR minus 19.4 million IDR) was 600,000 IDR (43 USD) which was related to $3.6 \%$ decrease of rehospitalization rate. It showed that 3.7 million IDR (264 USD) was needed for every increase of 1 score of ADL and 600,000 IDR (43 USD) was related to 3.6\% decrease in rehospitalization rate (Figure 2 ).

\section{DISCUSSION}

The median age of patients in the pre-UHCP and UHCP groups was similar to the demographic data of the elderly population in Indonesia. ${ }^{1}$ The characteristics of the main diagnosis in both groups were comparable. As widely known, the diagnosis is strongly linked to functional status and rehospitalization risk in the geriatric population..$^{10,11}$ The proportion of those aged $\geq 80$ years was similar between the two groups; the proportion of those who were with severe dependency as well as total dependency was also similar. These characteristics were important to be stressed out as the very old age and severe dependency or total dependency were highly associated with outcomes such as length of stay, changes of functional status and rehospitalization rate. ${ }^{6}$

Although the proportion of subjects with increased $A D L$ in both groups was relatively the same, the median of ADL difference between admission and discharge in the UHCP group (the score difference was 2) was higher than that in the pre-UHCP group (the score difference was 1). The proportion of patients being discharged with functional status of independent in the UHCP 
Figure 1. The comparison of dependency status during admission and discharge. $\mathrm{UHCP}=$ universal health coverage program

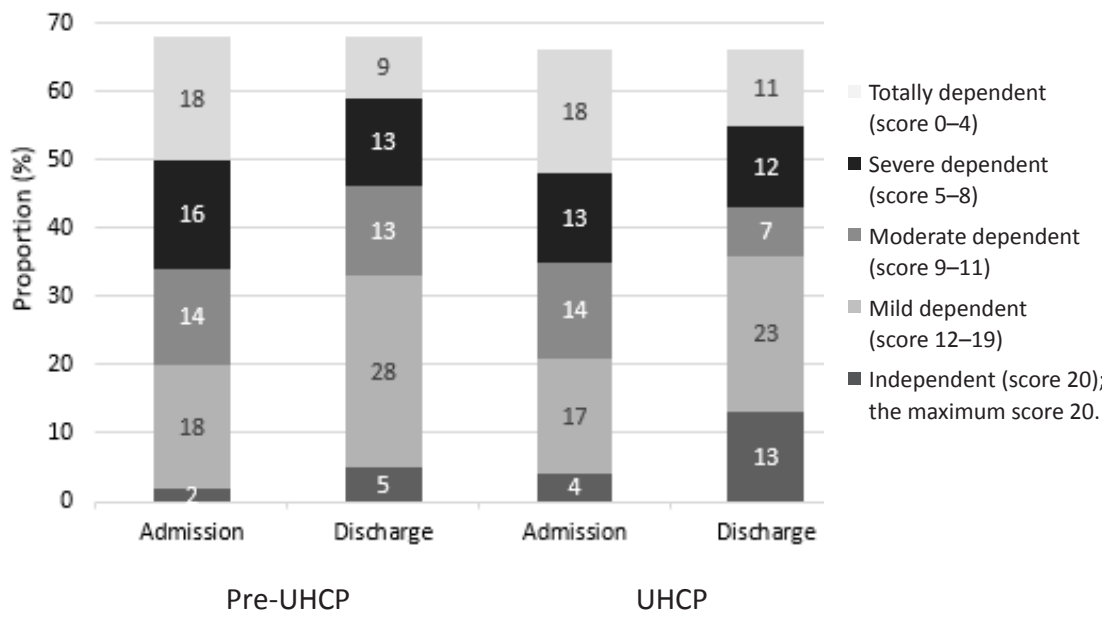

after discharge) declined from $21.7 \%$ to $18.1 \%$ after the implementation of UHCP. Zabawa et al ${ }^{5}$ also found $22.0 \%$ of the rehospitalization of elderly patients who survived after acute myocardial infarction. The research reported by Ogbemudia and Asekhame ${ }^{16}$ found that the rates of preventable rehospitalization due to non-adherent to medication and pneumonia were $23.4 \%$ and $20.5 \%$, respectively. However, those findings were not comparable to the study performed by Morandi et $\mathrm{al}^{17}$ that concluded the rate of rehospitalization was only $4 \%$. The research by Morandi et $\mathrm{a}^{17}$ was performed in an academic medical center with a full-time geriatric team that provides services for acute care setting with geriatric syndromes. The proportion of moderate to severe and totally dependent functional status during discharge in the pre-UHCP group (35/68 or $51.5 \%$ ) was higher than that in the UHCP group (30/66 or $45.5 \%$ ). The lower rate of moderately to severely and totally dependent functional status in the UHCP group might explain the reduction of the rehospitalization rate in the UHCP group. The increased dependency
Figure 2. Diagram of incremental costeffectiveness ratio (ICER) for functional status and rehospitalization. $X$-axis representing changes of functional status (differences of ADL Barthel index score) status ( $\mathbf{\Delta})$ and reduction of rehospitalization rate (\%) ( $(\bullet)$ before and after UHCP; $y$-axis representing hospital cost (in million IDR). UHCP=universal health coverage program

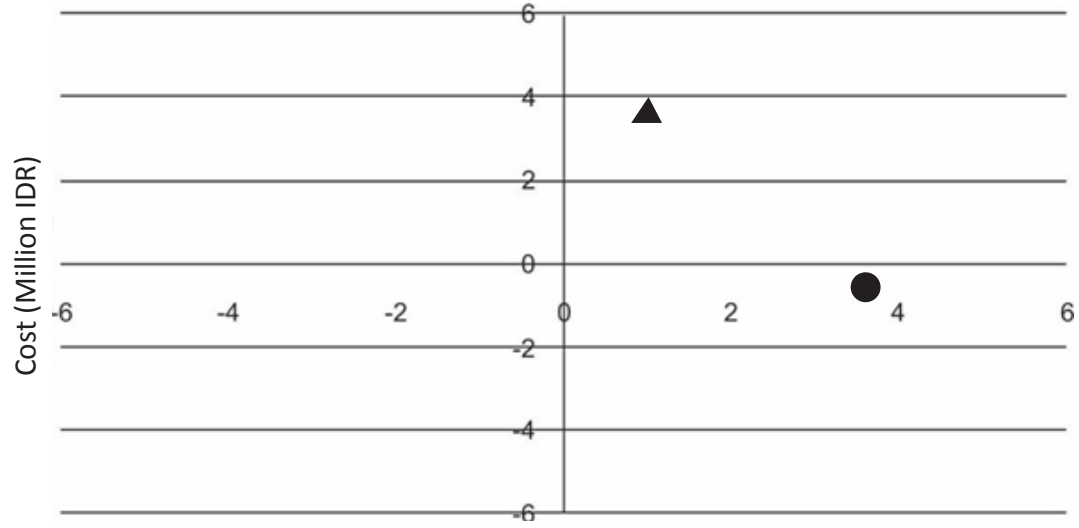

Changes before and after UHCP 
on functional status will increase the risk of rehospitalization. ${ }^{17,18}$

The implementation of UHCP would hopefully increase the efficacy of resource usage, as compared with the scheme of fee for service. In this study, the median of hospitalization cost in the UHCP group was 3.7 million IDR (264 USD), lower than that in the preUHCP group, and this finding was accompanied by an increase of 1 ADL score in the UHCP group. The rate of rehospitalization decreased by $3.6 \%$, and the cost was lower by 600,000 IDR (43 USD). Cheng et al7 reported that UHCP not only narrowed down the gap of health service access but also resulted in a good health-related outcome (functional status and rehospitalization), especially in the lower economic society, without increasing the cost. The research was constructed from the Chinese Longitudinal Healthy Longevity Survey collected by the Center for Healthy Aging and Development Studies at Peking University. It observed the ADL, quality of life, and other health outcomes after the implementation of the health insurance program by the government.

This study also review the process of comprehensive geriatric assessment itself both in pre-UHCP group and the UHCP group, which might play a role in the outcome measures. The similarities of functional status assessed by various professions before and after implementation of UHCP were equal (Table 4). The applicability of functional reablement process done by nurses was also congruent before and after the implementation of UHCP; this finding was also marked the equal CGA process on both groups. These result in process indicator were concordant with the basic principles of key components on the process of CGA. ${ }^{9}$

The present authors were aware of the study limitations. First, the observation period of this study was the first 6 months of the UHCP implementation. In such early months, the hospital was still trying to adapt and make an adjustment with the new health system, including its payment system. This issue might have an impact on outcomes. Second, the study was conducted in a national referral hospital, mostly with complicated geriatric cases, which was not necessarily representative of other hospitals in Indonesia. However, as up to now, only a few hospitals in Indonesia can provide geriatric care, and this was a good example. Third, even though the study used a good methodological approach, more subjects in the
UHCP group are needed, while the number of loss to follow-up subjects (16\%) was also a concern. Thus, wider scale research could be conducted in several other hospitals that provide geriatric care, with a longer observation period.

\section{Conclusions}

Within the first 6 months of implementation, the UHCP showed benefit with the reduction of rehospitalization rate and its consequence in hospital cost without the risk of decrease in functional status. This study highlighted that the UHCP could support efficient and effective hospital-based geriatric care.

\section{Conflict of Interest}

The authors affirm no conflict of interest in this study.

\section{Acknowledgment}

We thank to the President Director, the Medical Director, and the Director of Development and Promotion of Cipto Mangunkusumo Hospital, Jakarta. This study was supported by Geriatric Team, Nursing Team, and Rehabilitation Team of Cipto Mangunkusumo Hospital, Jakarta.

\section{Funding Sources \\ None.}

\section{REFERENCES}

1. BPS - Statistics Indonesia. Indonesia population projection 2010-2035. Jakarta: BPS - Statistics Indonesia; 2013. p. 40.

2. United Nations, Department of Economic and Social Affairs, Population Division (2013). World Population Prospects: The 2012 Revision, Key Findings and Advance Tables. Working Paper No. ESA/P/WP.227.

3. National Institute on Aging, National Institute of Health, US Department of Health and Human Services. Global health and aging. WHO, 2011:11-7717.

4. Hendarwan $\mathrm{H}$, Yuniar $\mathrm{Y}$, Despitasari M. Prospects, facts, and solution for Indonesia Universal health coverage program: indonesia health forum panell discussion. research and development board, Ministry of Health. 2018;7:11-7.

5. Zabawa C, Cottenet J, Zeller M, Mercier G, Rodwin VG, Cottin $\mathrm{Y}$, et al. Thirty-day rehospitalizations among elderly patients with acute myocardial infarction: impact of postdischarge ambulatory care. Medicine. 2018;97(24):e11085.

6. Hopman-Rock M, van Hirtum $H$, de Vreede $P$, Freiberger $E$. Activities of daily living in older community-dwelling persons: a systematic review of psychometric properties of instruments. Aging Clin Exp Res. 2019;31(7):917-25.

7. Ryg J, Engberg $\mathrm{H}$, Mariadas $\mathrm{P}$, Pedersen $\mathrm{SGH}$, Jorgensen MG, Vinding KL, et al. Barthel index at hospital admission is associated with mortality in geriatric petients: a Danish nationwide population-based cohort study. Clin Epidemiol. 2018;10:1789-800.

8. Parker SG, McCue P, Phelps K, McCleod A, Arora S, Nockels K, et al. What is comprehensive geriatric assessment (CGA)? an umbrella review. Age Ageing. 2018;47(11):149-55.

9. Ellis G, Gardner M, Tsiachristas A, Langhorne P, Burke O, Harwood RH, et al. Comprehensive geriatric assessment for older adults admitted to hospital. Cochrane Database Syst Rev. 2017;9:CDoo6211.

10. Unutmaz GD, Soysal P, Tuven B, Isik AT. Cost of medication 
in older patients: before and after comprehensive geriatric assessment. Clin Interv Aging. 2018;13:607-13.

11. Marventano S, Ayala A, Gonzalez N, Rodríguez-Blázquez C, Garcia-Gutierrez S, Forjaz MJ, et al. Multimorbidity and functional status in community-dwelling older adults. Eur $J$ Intern Med. 2014;25(7):610-6.

12. Cheng L, Liu H, Zhang Y, Shen K, Zeng Y. The impact of health insurance on health outcomes and spending of the elderly: Seminar in National School of Development and Peking University. JEL Classification: 118, D04. 2012: 1-36.

13. Alzahrani SH, Alamri SH. Prevalence of malnutrition and associated factors among hospitalized elderly patients in King Abdulaziz University Hospital, Jeddah, Saudi Arabia. BMC Geriatr. 2017;17(1):136.

14. Dharmarajan K, Hsieh AF, Lin Z, Bueno H, Ross JS, Horwitz $\mathrm{LI}$, et al. Diagnoses and timing of 30-day readmissions after hospitalization for heart failure, acute myocardial infarction, or pneumonia. JAMA. 2013;309(4):355-63.

15. Uchmanowicz I, Kuśnierz M, Wleklik M, Jankowska-Polańska $B$, Jaroch J, Łoboz-Grudzień K. Frailty syndrome and rehospitalizations in elderly heart failure patients. Aging Clin Exp Res. 2018;30(6):617-23.

16. Ogbemudia E, Asekhame J. Rehospitalization for heart failure in elderly. Saudi Med J. 2016;37(10):1144-7.

17. Morandi A, Bellelli G, Vasilevskis EE, Turco R, Guerini F, Torpilliesi $\mathrm{T}$, et al. Predictors of rehospitalization among elderly patients admitted to a rehabilitation hospital: the role of polypharmacy, functional status and length of stay. J Am Med Dir Assoc. 2014;14(10):761-7.

18. Greysen SR, Stijacic Cenzer I, Auerbach AD, Covinsky KE. Functional impairment and hospital readmission in Medicare seniors. JAMA Intern Med. 2015;175(4):559-65. 